\title{
СОСТАВ ГЕКСАН - ХЛОРОФОРМНОГО ЭКСТРАКТА ВЕРХОВЫХ ТОРФОВ ЮЖНОЙ ТАЙГИ ЗАПАДНОЙ СИБИРИ
}

\author{
() Ю.В. Коржов ${ }^{1}$, Н.Г. Коронатова ${ }^{2 *}$ \\ ${ }^{1}$ Югорский государственный университет, ул. Чехова, 16, Ханты-Мансийск, \\ 628011 (Россия), e-mail: ykor1962@mail.ru \\ ${ }^{2}$ Институт почвоведения и агрохимии СО РАН, ул. Советская, 18, \\ Новосибирск, 630099 (Россия), e-mail: coronat@mail.ru
}

\begin{abstract}
Представлены данные об элементном составе и содержании основных групп органических веществ, извлекаемых гексан-хлороформной (4 : 1 об.) смесью, в фускум-торфе и сфагновом мочажинном торфе с низкой степенью разложения, изъятых в южнотаежных верховых болотах Западной Сибири. Показано, что преобладающими группами являются алканы нормального строения и терпеноиды.

Ключевые слова: верховой сфагновый торф, газовая хромато-масс-спектрометрия, элементный состав торфа, гексан-хлороформный экстракт, групповой состав экстракта
\end{abstract}

\section{Введение}

Изучение элементного и химического состава торфов является актуальной задачей как в теоретическом, так и в практическом плане. Теоретическая значимость заключается в необходимости познания внутренних процессов трансформации органического вещества в торфяной залежи для понимания особенностей круговорота углерода в болотных экосистемах. Практическая значимость заключается в потенциальной возможности использования торфяного сырья в различных отраслях промышленности. Известно, что торф содержит разные группы органических соединений, в том числе биологически активные вещества, например, обладающие антиоксидантной $[1,2]$, фунгицидной и антимикробной активностью $[3,4]$, а также аминокислоты и набор витаминов [5]. Все это характеризует торф как ценный материал, на основе которого могут быть получены лечебно-профилактические средства.

Эти аспекты изучения болот приобретают особенную актуальность для западносибирского региона, который является наиболее заболоченной территорией мира с богатейшим запасом торфяных ресурсов. Изучение элементного и химического состава западносибирских торфов проводилось главным образом в южнотаежной подзоне. Было показано, что элементный состав верховых торфов Томской области представлен на 53,0-53,5\% углеродом, на 4,81-4,89\% - водородом, на 1,09-1,26\% - азотом, на 0,14-0,15\% серой и на 39,2-41,0\% - кислородом [6]. Интересно проследить вариации содержания битумов в верховых торфах Западной Сибири. В Кемеровской области битуминозность торфа составляет 2,5\%, из которых $1,6 \%$ приходится на восковую фракцию (в пересчете на сухой беззольный образец) [7, 8]; в торфе южнотаежной подзоны содержание битумов выше $-3,4-4,2 \%$ в расчете на горючую массу торфа [6]. Среднее содержание битумов в западносибирском фускум-торфе и близком к нему по составу и свойствам верховом

Коржов Юрий Владимирович - доцент кафедры геологии, кандидат химических наук, тел.: (3467) 35-76-65, e-mail: ykor1962@ mail.ru Коронатова Наталья Геннадьевна - научный сотрудник, кандидат биологических наук, тел.: (383) 222-54-15, e-mail: coronat@ mail.ru комплексном торфе, которые характеризуются низкой степенью разложения, составляет 4,2\% при варьировании от 2,0 до 10,0\% [9]. По результатам инфракрасной спектроскопии, полученным С.И. Жеребцовым с соавт. [7, 8], восковая фракция верхового торфа представлена смесью свободных карбоновых

\footnotetext{
* Автор, с которым следует вести переписку.
} 
кислот, их солей и сложных эфиров, а также жирными спиртами и высшими алканами. Компонентный состав веществ той же восковой фракции по данным газовой хромато-масс-спектрометрии (ГХ-МС) отличается отсутствием эфиров карбоновых кислот, что, вероятно, связано со спецификой данного метода: либо в инжекторе-испарителе происходит термическая деструкция исходных молекул, приводящая к появлению осколочных молекул, либо «тяжелые» молекулы необратимо сорбируются в хроматографической колонке.

Цель данной работы - изучить элементный состав и выявить основные группы органических веществ, экстрагируемых гексан-хлороформной смесью растворителей (4 : 1 по объему) из верховых торфов южной тайги Западной Сибири.

\section{Экспериментальная часть}

Объектыл. Объектами исследования являлись два вида верхового торфа - фускум-торф и сфагновый мочажинный (согласно классификации С.Н. Тюремнова [10]). Торфы были отобраны в экосистемах Бакчарского болота (56 $51^{\prime}$ с.ш., 8250’ в.д.), которое находится в пределах Томской области и относится к северо-восточным отрогам Большого Васюганского болота. Фускум-торф был взят в сосновокустарничково-сфагновом сообществе ряма, $\mathrm{pH}$ болотных вод соответствовала значению 3,8. Сфагновый мочажинный торф - в примыкающей к ряму обводненной топяной экосистеме с пушицево-сфагновым сообществом, и рН болотных вод равен 3,9. Характеристика изучаемых торфов приведена в таблице 1 . Монолиты торфа изымались с глубины 40-60 см, затем эти образцы очищались от наиболее крупных инородных объектов (кусков древесины, крупных живых корневищ и прочего). Далее торф высушивали в сушильном шкафу при температуре $60{ }^{\circ} \mathrm{C}$ и измельчали на лабораторной мельнице ЛЗМ-1. В последующем образцы торфа хранили в сухих бумажных пакетах.

Таблица 1. Общая характеристика торфов, \%

\begin{tabular}{l|c|c|c}
\hline \multicolumn{1}{c|}{ Вид торфа } & Зольность & Степень разложения & Ботанический состав \\
\hline $\begin{array}{l}\text { Сфагновый } \\
\text { мочажинный торф }\end{array}$ & 1,4 & $10-15$ & $\begin{array}{c}\text { Sphagnum fallax }-95,2 \pm 0,5, \\
\text { Живые корни Eriophorum vaginatum }-4,8 \pm 0,5 \\
\text { Sphagnum fuscum }-98,9 \pm 0,1,\end{array}$ \\
Фускум-торф & 2,4 & $5-10$ & Живые корни кустарничков $-1,1 \pm 0,1$ \\
\hline
\end{tabular}

Оборудование и условия проведения анализа. Определение содержания углерода, водорода и азота в торфах проводилось на CNHS/O-анализаторе Perkin Elmer 2400 Series II (США).

Анализ экстрактивных веществ торфов осуществляли методом газовой хромато-масс-спектрометрии на газовом хроматографе Clarus 500 MS фирмы Perkin Elmer (США) с квадрупольным детектором. Применяли колонку аналитическую капиллярную 30 м × 0,25 мм с неподвижной фазой Elite-5MS (метилполисилоксан, 5\% фенил) и толщиной пленки 0,2 мкм. Начальная температура колонки была $40{ }^{\circ} \mathrm{C}$ в течение 5 мин, затем со скоростью $5{ }^{\circ} \mathrm{C} /$ мин температура увеличивалась до $310{ }^{\circ} \mathrm{C}$. Газ-носитель - гелий. Температура источника электронов $190{ }^{\circ} \mathrm{C}$, температура инжектора $220^{\circ} \mathrm{C}$, трансферлайна $300{ }^{\circ} \mathrm{C}$, энергия электронов 70 эВ.

Подготовка проб к ГX-MC анализу. Согласно модифицированным методикам TNRCC Method 1005 и МУК 4.1.663-97, применяемым для определения органических соединений в объектах окружающей среды $[11,12]$, навеску сухого измельченного торфа массой около 2.0 г помещали в коническую колбу, приливали 20 мл смеси хлороформа с гексаном (1: 4 по объему), перемешивали в течение 10 мин при комнатной температуре, смесь отстаивали в течение 30 мин при комнатной температуре, после чего фильтровали через беззольный фильтр марки «синяя лента». Экстракцию повторяли трижды, экстракты объединяли. Затем объединенный экстракт концентрировали на ротационном испарителе в вакууме водоструйного насоса при температуре водяной бани $40{ }^{\circ} \mathrm{C}$ до 1 мл, количественно переносили в виалы объемом 2 мл и отдували остатки растворителя в токе азота при температуре $20^{\circ} \mathrm{C}$. Полученный сухой остаток растворяли в 100 мкл хлороформа и вводили внутренний градуировочный стандарт - 1 мкл раствора аценафтена-d $\mathrm{d}_{10}$ в хлороформе с концентрацией 1,18 мкг/мкл. Для анализа экстрактов торфа в хроматограф вводили 1 мкл полученного таким образом раствора.

Качественный и количественный анализ. Идентификацию веществ проводили по относительным временам удерживания и по библиотеке масс-спектров, имеющейся в программном обеспечении к прибоpy: NIST, Wiley и Pfleger/Maurer/Weber. Гомологические ряды групп веществ выявляли путем реконструи- 
рования исходной хроматограммы по характеристическим ионам, известным из литературы [12, 13], а также установленным в ходе проведения данного исследования.

Концентрации веществ определяли по внутреннему стандарту - аценафтену-d $\mathrm{d}_{10}$. Содержание углеводородов в пересчете на сухой торф рассчитывали по формуле

$$
\mathrm{m}_{\mathrm{i}}=\frac{S_{i} \cdot m_{s t}}{m \cdot S_{s t}} \cdot \frac{V_{\ni}}{V a}
$$

где $\mathrm{m}_{\mathrm{i}}$ - концентрация определяемого вещества (мкг/г), $m_{\mathrm{st}}-$ масса внутреннего стандарта (мкг); $m-$ навеска торфа (г); $S_{\mathrm{i}}$ - площадь пика определяемого вещества (усл. ед.); $S_{\mathrm{st}}$ - площадь пика стандарта (усл. ед.); $V_{\ni}$ - общий объем экстракта (мл); $V_{\text {a }}$ объем аликвоты экстракта, полученного после фильтрования (мл).

\section{Обсуждение результатов}

Битумные и другие сопутствующие органические вещества извлекались из торфа гексан-хлорофомной смесью растворителей (4 : 1 по объему). Выбор данного экстрагента был обусловлен составом битумоидов торфа, к которым относятся главным образом неполярные и среднеполярные соединения: предельные и непредельные углеводороды, высокомолекулярные органические кислоты и жирные спирты, их сложные эфиры, воски, смолы, масла [14].

Результаты элементного анализа торфов приведены в таблице 2. Полученные данные типичны для элементного состава верховых торфов.

После экстрагирования органических соединений из торфов гексан-хлороформной смесью масса сухих экстрактов составила 0,46 и $0,55 \%$ от абсолютно сухого вещества фускум-торфа и мочажинного торфа соответственно. Суммарное количество веществ, доступных ГХ-МС исследованию (прошедшие хроматографическую систему и представленные на хроматограмме), составило около 50\% от общей массы экстрактов. Всего было зарегистрировано 166 индивидуальных пиков. Общий вид хроматограммы для обоих торфов приведен на рисунке 1. Время анализа составило 72-75 мин, наиболее легкие вещества фиксировались с 17 мин, с 29 по 55 мин. интенсивность появления пиков была относительно постоянной, а максимальное число пиков появилось на хроматограмме в период с 55 по 65 мин, когда стали детектироваться наиболее тяжелые молекулы с молекулярной массой более 400.

Полученные данные о содержании классов и групп органических соединений в экстракте приведены в таблице 3. Ряд компонентов, обнаруженных в составе экстрактов, не удалось точно идентифицировать ввиду отсутствия масс-спектров соответствующих веществ в использованной электронной базе масс-спектров органических соединений. Однако для большинства таких соединений достаточно надежно определена их принадлежность к определенным классам или группам органических веществ. Из идентифицированных соединений преобладающими группами были терпеноиды и парафины (нормальные жирные алканы).

Содержание $\boldsymbol{\mu}$-алканов в обоих торфах было сходно. Соотношение соединений с четным и нечетным количеством атомов углерода в молекуле приведено на рисунке 2. Для изученных торфов характерно бимодальное распределение $\boldsymbol{H}$-алканов с максимумами, приходящимися на $\mathrm{C}_{16} \mathrm{C}_{25}-\mathrm{C}_{31}$. Длина гомологического ряда составила $\mathrm{C}_{39}$ для мочажинного торфа и $\mathrm{C}_{33}$ - для фускум-торфа. Отношение содержания алканов с нечетным количеством атомов углерода к молекулам с четным числом (индекс CPI - carbon preference index [15]) было 2.0 - для мочажинного торфа и 2.9 - для фускум-торфа, т.е. для экстрактов обоих торфов содержание в них углеводородов с нечетным количеством атомов углерода в молекуле $\left[\mathrm{C}_{2 n+1} \mathrm{H}_{4 n+4}\right]$ было в 2 и более раза выше, чем алканов с четным количеством атомов углерода $\left[\mathrm{C}_{2 \mathrm{~m}} \mathrm{H}_{4 \mathrm{~m}+2}\right]$. При этом относительное содержание «нечетных» углеводородов в сравнении с «четными» оказалось выше в фускум-торфе. Интересно, что для алканов с молекулярной массой от $\mathrm{C}_{22}$ до $\mathrm{C}_{33}$ индекс СРI возрос в торфах до 9,1-9,6. Несмотря на преобладание алканов с нечетным числом атомов углерода в молекуле, свидетельствующее об их происхождении от высших растений (в данном случае - мхов), максимальное содержание пришлось на цетан $\mathrm{C}_{16} \mathrm{H}_{34}$, площадь пика которого была наибольшей (23\% в мочажинном торфе и $15 \%$ в фускум-торфе от содержания всех $\boldsymbol{H}$-алканов). Согласно литературным данным [16], источником цетана в торфах могут являться различные микроорганизмы, главным образом аэробные бактерии и низшие грибы. Отметим, что содержание цетана составило 12,0 и 7,0 мкг/г торфа для мочажинного и фускум-торфа, соответственно, что может косвенно указывать на более высокую численность аэробных микроорганизмов в олиготрофной мочажине на глубине 40-60 см 
по сравнению с рямом. Возможно, это связано с частично аэробными условиями в зоне развития корневых систем трав [17], несмотря на относительно высокий уровень болотных вод, который здесь не опускался ниже 25 см за несколько лет наблюдений. Полученные данные о более высоком содержании цетана в мочажине по сравнению с рямом согласуются с имеющимися в литературе результатами исследования микромицетного комплекса аналогичных экосистем этого же болота: концентрация микромицетов в верхнем полуметровом слое была 2-8 и 2-26 мг/г торфа, а общий запас грибной биомассы во всей толще торфа 0,3-0,5 и 0,5-1,2 кг/м² в ряме и открытой топи соответственно [18].

Алканы изопреноидного строения были представлены пристаном, фитаном и некоторыми другими, которые обнаружены в количестве 0,4 мкг/г абс. сух. торфа в фускум-торфе и 0,8 - в мочажинном.

Циклогексаны и циклопентаны не были обнаружены в нашем исследовании, возможно, вследствие методических погрешностей, поскольку данные соединения являются легколетучими веществами.

Таблица 2. Элементный состав торфов в пересчете на абсолютно сухой образец

\begin{tabular}{l|c|c|c|c}
\hline \multicolumn{1}{c|}{ Вид торфа } & $\mathrm{C}, \%$ & $\mathrm{~N}, \%$ & $\mathrm{H}, \%$ & $\mathrm{O}+\mathrm{S}, \%$ \\
\hline Сфагновый мочажинный торф & 48.6 & 0.7 & 6.6 & 42.7 \\
Фускум-торф & 48.3 & 0.6 & 6.4 & 42.3 \\
\hline
\end{tabular}
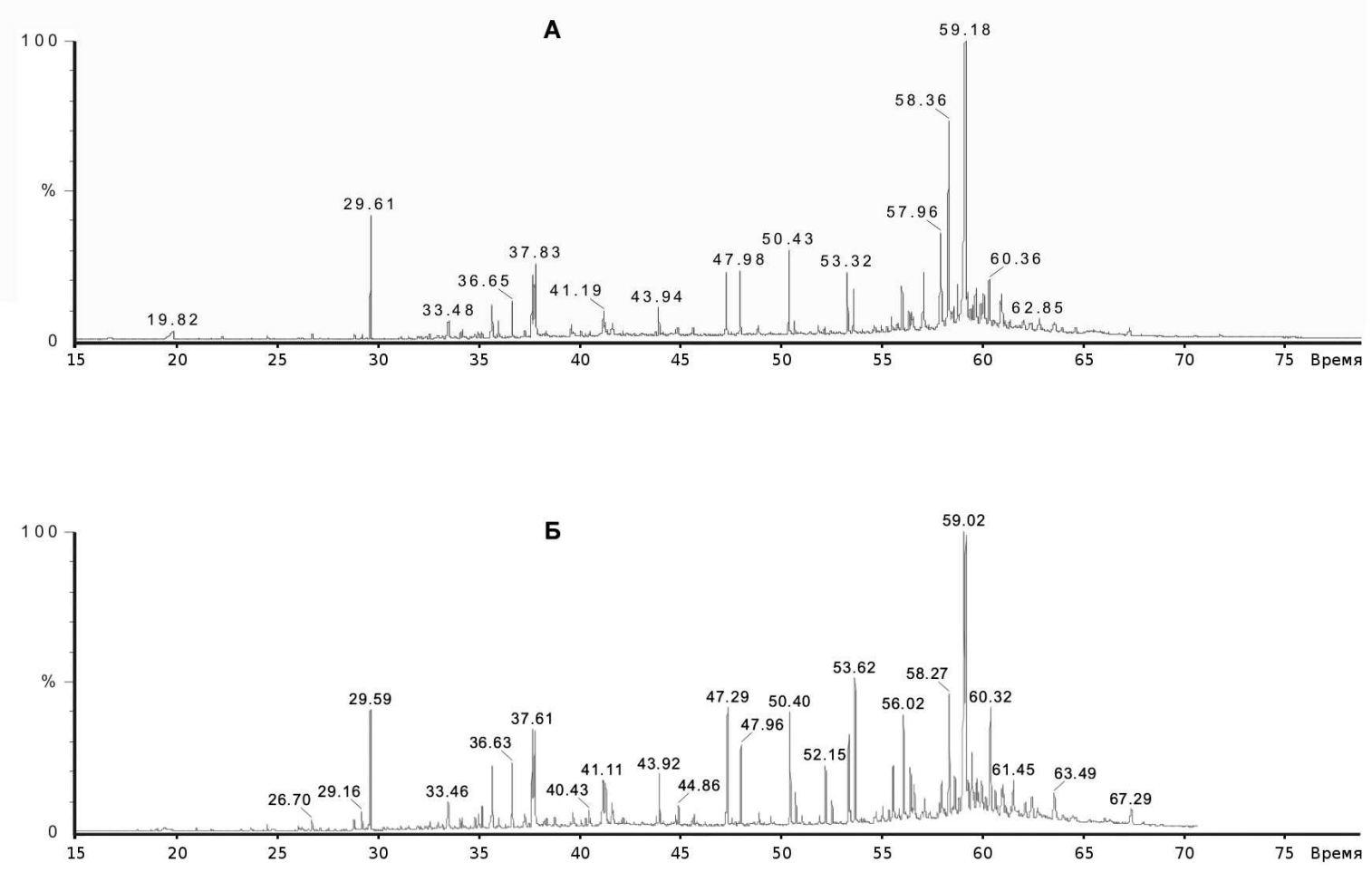

Рис. 1. Общий вид хроматограмм гексан-хлороформных экстрактов торфов, полученных в условиях газовой хромато-масс-спектрометрии: А - мочажинный торф, Б - фускум-торф

Таблица 3. Состав экстрактивных веществ торфов согласно ГХ-МС анализу, \% от массы экстракта

\begin{tabular}{l|c|c}
\hline \multicolumn{1}{c|}{ Классы и группы веществ } & Мочажинный торф & Фускум-торф \\
\hline Нормальные алканы & 10,1 & 11,2 \\
Терпеноиды & 18,1 & 2,4 \\
Токоферолы & 0,6 & 4,3 \\
Карбоновые кислоты & 4,4 & 5,3 \\
Кетоны & 1,8 & 0,05 \\
Биарены и триарены & 0,04 & 14,1 \\
Неидентифицированные соединения & 16,1 & \\
\hline
\end{tabular}


Терпеноиды на хроматограммах имели пики с временами удерживания 56 мин и выше. Определение их принадлежности к данной группе было осуществлено по электронной библиотеке масс-спектрометрических данных. В большинстве случаев терпеноиды относились к тритерпенам и политерпенам, включали стерины. Эта группа экстрактивных веществ оказалась первой по массовой доле от всех идентифицированных органических соединений.

Токоферолы (витамин Е) также определялись по электронной библиотеке масс-спектрометрических данных, для них характеристичным являлся осколочный ион с m/z 165 . Они были представлены $\beta$ - и $\gamma$-токоферолом, а также $\alpha$-токоферолом. Содержание последнего было в 1,2 раза ниже по сравнению с $\beta$ - и $\gamma$-токоферолом в мочажинном торфе, и в 3,7 раз - в фускум-торфе. Полученные в данной работе оценки содержания витамина Е в фускум-торфе оказались в 2 раза выше, а в мочажинном торфе - немного ниже в сравнении с данными по щелочному экстракту низинного торфа [5].

Карбоновые кислоты определялись по характеристическим ионам m/z 60+73+129 и были представлены гомологическим рядом монокарбоновых кислот, включая молекулы с числом атомов углерода $\mathrm{C}_{8}-\mathrm{C}_{18}$ (рис. 3). Наибольшее содержание было отмечено для пальмитиновой кислоты $\mathrm{C}_{15} \mathrm{H}_{31} \mathrm{COOH}$, которая широко распространена в природе (особенно высоко ее содержание в микроорганизмах), при этом ее концентрация в мочажинном торфе была в 1,4 раза выше, чем в фускум-торфе. Суммарное содержание остальных ее гомологов было практически одинаковым - 9,0 и 9,1 мкг/г абсолютно сухого торфа в фускум-торфе и мочажинном. Вероятно, высокая концентрация в экстрактах $\mu$-алкана цетана $\mathrm{C}_{16}$ обусловлена именно превалированием пальмитиновой кислоты, которая оказывается генетически связанной с ним.

Суммарное содержание кетонов, определенных по характеристичным ионам m/z 58+59, составило 23,9 мкг/г в фускум-торфе и 9,8 мкг/г в мочажинном торфе, т.е. в первом случае их содержание было в 2,4 раза выше. Хроматографический анализ показывает, что среди идентифицированных кетонов распространены молекулы с числом атомов углерода от $\mathrm{C}_{21}$ до $\mathrm{C}_{32}$ с максимальным содержанием $\mathrm{C}_{27}$-кетона, на долю которого приходится 49 и $43 \%$ в мочажинном и фускум-торфе, соответственно (рис. 4).

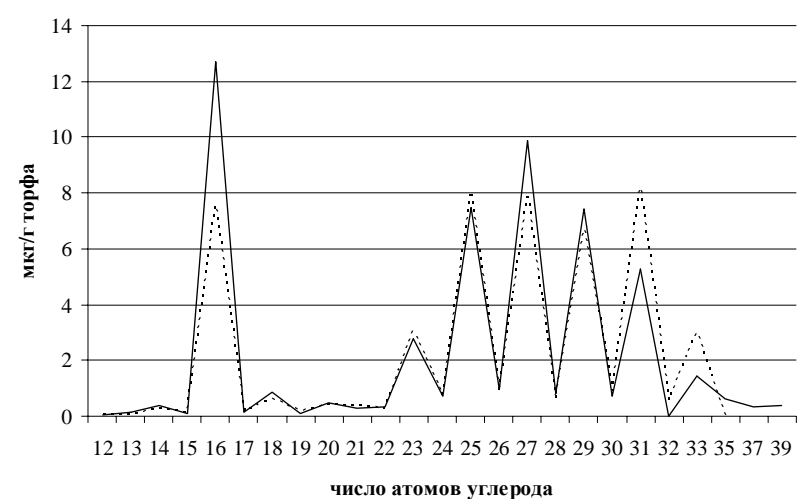

Рис. 2. Концентрации гомологов ряда $\boldsymbol{t}$-алканов. Сплошная линия - мочажинный торф, пунктирная линия - фускум-торф

Рис. 4. Концентрации гомологичных кетонов. Сплошная линия - мочажинный торф, пунктирная линия - фускум-торф

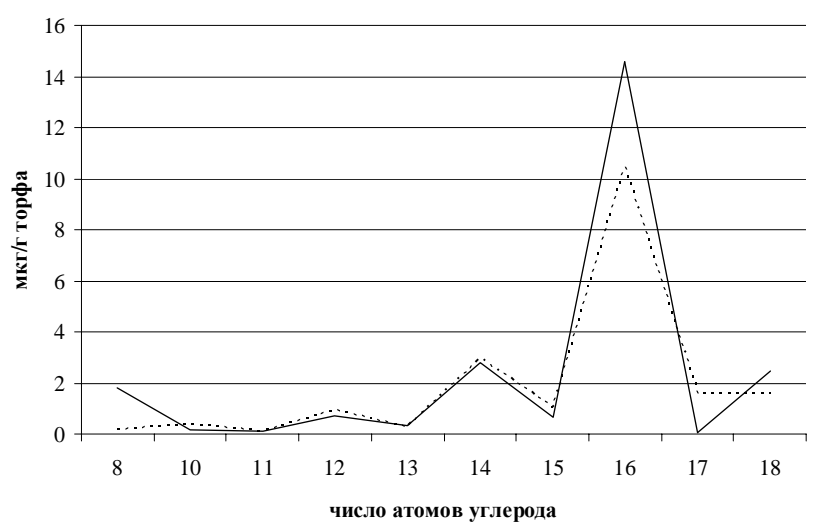

Рис. 3. Концентрации гомологов ряда жирных кислот. Сплошная линия - мочажинный торф, пунктирная линия - фускум-торф

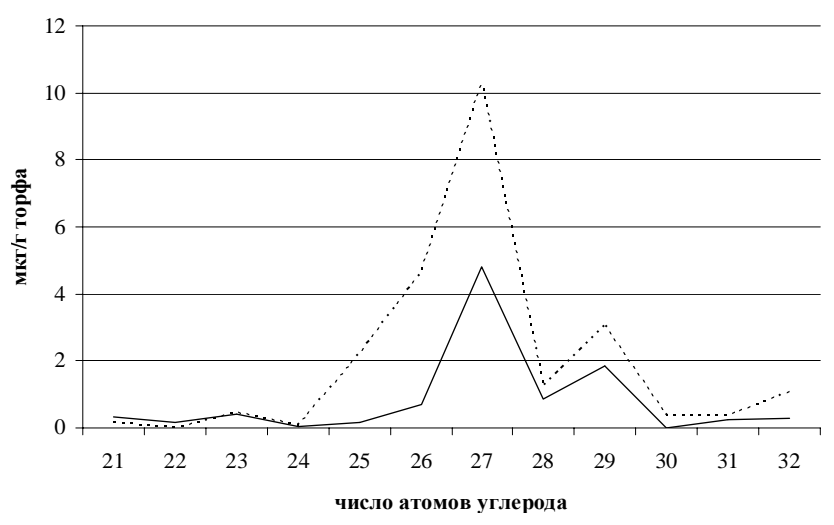


Кроме перечисленных выше веществ, идентифицированных в экстрактах, в хроматограммах наблюдались слабые пики ароматических углеводородов, которые представлены в основном биядерными (нафталины) и триядерными аренами (фенантрены). Нафталины $\mathrm{C}_{10}-\mathrm{C}_{12}$ выявлялись по молекулярным ионам $\mathrm{m} / \mathrm{z}$ $128+142+156$ и ряду осколочных ионов m/z 115, 77, 78 и др., фенантрены - по молекулярным ионам с m/z 178+192. Концентрация каждой группы не превысила 0,1 мкг/г в обоих торфах. Их содержание было минимальным среди выявленных групп органических соединений. Вместе с тем алкилбензолы не были обнаружены в экстрактах, хотя имеются литературные сведения, указывающие на их наличие в торфах сходного генезиса. Так, отмечалось, что их количество в верхнем полуметровом слое фускум-торфа значительно меньше, чем нафталинов и фенантренов [16]. Полициклоарены с числом циклов более 3 не были идентифицированы в нашем исследовании, хотя в западносибирских торфах фиксировалось их наличие в концентрации, не превышающей 0.05 мкг/г [16].

Группа неидентифицированных соединений составила от четверти до трети всего экстракта. В эту группу вошли также спирты, точное количественное содержание которых не было установлено, однако по предварительной оценке на их долю приходится около $2 \%$ от массы экстракта.

\section{Выводы}

Элементные составы мочажинного и фускум-торфа типичны для верховых торфов.

Среди идентифицированных соединений в групповом составе гексан-хлороформного (4 : 1 об.) экстракта в наибольшем количестве (более 10\%) представлены $H$-алканы и терпеноиды . Преобладают нечетные $н$-алканы с числом атомов от $\mathrm{C}_{23}$ до $\mathrm{C}_{33}$, а также цетан $\left(\mathrm{C}_{16}\right)$. Другой преобладающей группой были соединения с большой молекулярной массой - терпеноиды.

В количестве от 1 до 5\% присутствуют карбоновые кислоты (с максимумом $\mathrm{C}_{16}$ ), кетоны (с максимумом $\mathrm{C}_{27}$ ) и токоферолы.

В незначительном количестве представлены би- и триарены.

\section{Благодарности}

Авторы выражают сердечную признательность канд. хим. наук Андрею Михайловичу Чибиряеву (НИОХ СО РАН) за любезную помощь в подготовке статьи, ценные замечания и полезные советы.

\section{Список литературы}

1. Исматова Р.Р., Федько И.В. Химические свойства и антиоксидантная активность торфа // Башкирский химический журнал. 2008. Т. 15, №1. С. 34-35.

2. Федько И.В., Гостищева М.В., Исматова Р.Р. Сравнительное изучение химического состава и биологической активности торфа в зависимости от степени его разложения // Химия растительного сырья. 2008. №1. С. 127-130.

3. Юдина Н.В., Писарева С.И., Зверева А.В., Дмитрук С.Е., Калинкина Г.И. Полисахариды из торфов и мхов // Химия растительного сырья. 1999. №4. С. 97-100.

4. Зайцева Т.Л., Навоша Ю.Ю., Шеремет Л.С., Пармон С.В. Усовершенствованный метод количественного определения биологически активных тритерпеноидов в экстрактах торфа и растений-торфообразователей // Химия растительного сырья. 2000. №4. С. 35-37.

5. Жилякова Т.П., Касимова Л.В. Влияние химических свойств торфов на состав щелочного экстракта // Химия растительного сырья. 2003. №3. С. 35-39.

6. Архипов В.С., Маслов С.Г. Состав и свойства типичных видов торфа центральной части Западной Сибири // Химия растительного сырья. 1998. №4. С. 9-16.

7. Жеребцов С.И., Мусин Ю.В., Моисеев А.И. Состав битумов алкилированного торфа // Химия твердого топлива. 2009. №3. С. 16-18.

8. Жеребцов С.И., Мусин Ю.В., Моисеев А.И. Влияние алкилирования на состав и выход битумоидов торфа // Химия растительного сырья. 2009. №2. С. 125-130.

9. Шинкеева Н.А., Маслов С.Г., Архипов В.С. Характеристика группового состава органического вещества отдельных репрезентативных торфов таежной зоны Западной Сибири // Вестник ТГПУ. 2009. Вып. 3. С. 116-119.

10. Тюремнов С.Н. Торфяные месторождения. 3-е изд., перераб. и доп. М., 1976. С. 139-181.

11. Кульков М.Г., Артамонов В.Ю., Коржов Ю.В., Углев В.В. Индивидуальные органические соединения нефти как индикаторы техногенного нефтяного загрязнения водной среды // Известия Томского политехнического университета. Геоэкология. 2010. Т. 317, №1. С. 195-200.

12. МУК 4.1.663-97. Определение массовой концентрации органических соединений в воде методом хроматомасс-спектрометрии. Методические указания. 
13. Лебедев А.Т. Масс-спектрометрия в органической химии. М., 2003. 493 с.

14. Раковский В.Е., Пигулевская Л.В. Химия и генезис торфа. М., 1978. 232 с.

15. Hsieh M., Philp P.R. Ubiquitous occurrence of high molecular weight hydrocarbons in crude oils // Organic Geochemistry. 2001. Vol. 32. Pp. 955-966.

16. Serebrennikova O.V., Preis Yu.I., Kadychagov P.B., Gulaya E.V. Hydrocarbon composition of the organic matter of peats in the south of Western Siberia // Solid Fuel Chemistry. 2010. V. 44, N5. Pp. 324-334.

17. Frolking, S., Roulet, N.T., Moore, T.R., Richard, P.J.H., Lavoie, M., Muller, S.D. Modeling northern peatland decomposition and peat accumulation // Ecosystems. 2001. Vol. 4. Pp. 479-498.

18. Головченко А.В., Семёнова Т.А., Полякова А.В., Инишева Л.И. Структура микромицетного комплекса олиготрофных торфяников южно-таежной подзоны Западной Сибири // Микробиология. 2002. Т. 71, №5. С. 667-674.

Поступило в редакиию 12 июля 2012 г.

После переработки 18 декабря 2012 г.

Korzhov Yu.V. ${ }^{l}$, Koronatova N.G. ${ }^{2^{*}}$ THE COMPOSITION OF HEXANE-CHLOROFORM EXTRACT OF OMBROTROPHIC PEATS OF SOUTHERN TAIGA OF WESTERN SIBERIA

${ }^{1}$ Ugra State University, ul. Chekhova, 16, Khanty-Mansiysk, 628011 (Russia), e-mail: ykor1962@mail.ru

${ }^{2}$ Institute of Soil Science and Agricultural Chemistry of SB RAS, ul. Sovetskaia, 18, Novosibirsk, 630099 (Russia),

e-mail: coronat@mail.ru

The paper presents data on the elemental composition and content of the major groups of organic substances extracted by hexane-chloroform (4:1 vol.) mixture in a fuscum peat and a sphagnum hollow peat with a low degree of decomposition, collected from the southern taiga ombrotrophic bogs of Western Siberia. It is shown that the dominant groups are the follows: alkanes of normal structure, carotenoids and terpenoids.

Keywords: ombrotrophic Sphagnum peats, gas chromatography-mass spectrometry, elemental composition of peat, hexane-chloroform extract, the extract group composition

\section{References}

1. Ismatova R.R., Fed'ko I.V. Bashkirskii khimicheskii zhurnal, 2008, vol. 15, no. 1, pp. 34-35. (in Russ.).

2. Fed'ko I.V., Gostishcheva M.V., Ismatova R.R. Khimiia rastitel'nogo syr'ia, 2008, no. 1, pp. 127-130. (in Russ.).

3. Iudina N.V., Pisareva S.I., Zvereva A.V., Dmitruk S.E., Kalinkina G.I. Khimiia rastitel'nogo syria, 1999, no. 4, pp. 97-100. (in Russ.).

4. Zaitseva T.L., Navosha Iu.Iu., Sheremet L.S., Parmon S.V. Khimiia rastitel'nogo syr'ia, 2000, no. 4, pp. 35-37. (in Russ.).

5. Zhiliakova T.P., Kasimova L.V. Khimiia rastitel'nogo syr'ia, 2003, no. 3, pp. 35-39. (in Russ.).

6. Arkhipov V.S., Maslov S.G. Khimiia rastitel'nogo syr'ia, 1998, no. 4, pp. 9-16. (in Russ.).

\footnotetext{
* Corresponding author.
} 
7. Zherebtsov S.I., Musin Iu.V., Moiseev A.I. Khimiia tverdogo topliva, 2009, no. 3, pp. 16-18. (in Russ.).

8. Zherebtsov S.I., Musin Iu.V., Moiseev A.I. Khimiia rastitel'nogo syr'ia, 2009, no. 2, pp. 125-130. (in Russ.).

9. Shinkeeva N.A., Maslov S.G., Arkhipov V.S. Vestnik TGPU, 2009, no. 3, pp. 116-119. (in Russ.).

10. Tiuremnov S.N. Torfianye mestorozhdeniia. [Peatlands]. Moscow, 1976, pp. 139-181. (in Russ.).

11. Kul'kov M.G., Artamonov V.Iu., Korzhov Iu.V., Uglev V.V. Izvestiia Tomskogo politekhnicheskogo universiteta. Geoekologiia, 2010, vol. 317, no. 1, pp. 195-200. (in Russ.).

12. MUK 4.1.663-97. Opredelenie massovoi kontsentratsii organicheskikh soedinenii v vode metodom khromato-massspektrometrii. Metodicheskie ukazaniia. [MUK 4.1.663-97. Determination of the mass concentration of organic compounds in water by gas chromatography-mass spectrometry. Methodical instructions.]. (in Russ.).

13. Lebedev A.T. Mass-spektrometriia v organicheskoi khimii. [Mass spectrometry in organic chemistry]. Moscow, 2003, 493 p. (in Russ.).

14. Rakovskii V.E., Pigulevskaia L.V. Khimiia i genezis torfa. [Chemistry and genesis of peat.]. Moscow, 1978, 232 p. (in Russ.).

15. Hsieh M., Philp P.R. Organic Geochemistry, 2001, vol. 32, pp. 955-966.

16. Serebrennikova O.V., Preis Yu.I., Kadychagov P.B., Gulaya E.V. Solid Fuel Chemistry, 2010, vol. 44, no. 5, pp. $324-334$.

17. Frolking, S., Roulet, N.T., Moore, T.R., Richard, P.J.H., Lavoie, M., Muller, S.D. Ecosystems, 2001, vol. 4, pp. 479-498.

18. Golovchenko A.V., Semenova T.A., Poliakova A.V., Inisheva L.I. Mikrobiologiia, 2002, vol. 71, no. 5, pp. 667-674.

Received Jule 12, 2012

Revised December 18, 2012 